\title{
PHOTOACTIVE POLYACRYLONITRILE FIBERS COATED BY NANO-SIZED TITANIUM DIOXIDE: SYNTHESIS, CHARACTERIZATION, THERMAL INVESTIGATION
}

\author{
HADI FALLAH MOAFI, ABDOLLAH FALLAH SHOJAIE* AND_MOHAMMAD ALI ZANJANCHI_
}

\author{
Department of Chemistry, Faculty of Science, University of Guilan, P.O.Box 1914, Rasht, Iran
}

(Received: November 16, 2009 - Accepted: January 20, 2011)

\begin{abstract}
Anatase nanocrystals were successfully synthesized and deposited onto polyacrylonitrile fibers with photocatalytic self-cleaning activity using the sol-gel process at low temperature. The original and treated samples have been characterized by several techniques such as scanning electron microscopy, fourier transform infrared spectroscopy, x-ray diffraction, diffuse reflectance spectroscopy, thermogravimetric analysis and differential scanning calorimetry. The TiO nanoparticles, have been found to form a homogeneous thin film on the fiber surface. The photocatalytic activity, tested by measuring the degradation of adsorbed Eosin Yellowish dye. The photoactivity of the titanium dioxide coated fibres is much higher than that observed in case of untreated fibers. The photocatalytic selfcleaning properties of the treated fibers was fully maintained performing several cycles of photodegradation. This preparation technique can be also applied to new fabrics to create self-cleaning properties in them. The thermogravimetric study of $\mathrm{PAN} / \mathrm{TiO}_{2}$ composite showed a slight increase of weight loss in the second step, which implied that, the dehydrogenation and oxygen uptake reactions would be promoted by the $\mathrm{TiO}_{2}$ to some extent.
\end{abstract}

Keywords: Polyacrylonitrile; Titanium dioxide; Thermogravimetric analysis; Differential scanning calorimetry; Photodegradation; Eosin Yellowish

\section{INTRODUTION}

Polyacrylonitrile (PAN) is one of the most widely used precursor polymers for making high performance carbon fibers [1-5]. Study of the degradation of polyacrylonitrile has been a subject of interest for decades owing to its commercial value for the production of carbon fibers [6-10]. Spectroscopy, including infrared, ultraviolet, solid-state nuclear magnetic resonance (NMR) and x-ray photoelectron spectroscopy (XPS), and thermal analysis, including differential scanning calorimetry (DSC), differential thermal analysis (DTA) and thermogravimetric analysis (TGA), are the common tools in the study of polyacrylonitrile degradation [11-14].

Semiconductor photocatalysis has been gathering much attention recently due to its promising application in chemical conversion and storage of solar energy for solar cells, hydrogen production, refractory pollutants elimination and self-cleaning surface [15-18].

Among various oxide semiconductor photocatalysts, titanium oxide $\left(\mathrm{TiO}_{2}\right)$ has been proven so far to be the most promising material used for both fundamental research and practical applications. Because of its highly efficient photoreactivity, biological and chemical inertness, cost effectiveness, non-toxicity, and long-term stability against photocorrosion and chemical corrosion, titanium dioxide has been frequently employed in the environmental treatment and purification purposes [18-22]. Anatase $\mathrm{TiO}_{2}$ has been identified as the most effective and useful photocatalyst under near UV illumination [23].

The pairs of free electrons and holes are formed in the conduction and valence band region of $\mathrm{TiO} 2$ under the UV irradiation, which react with oxygen and adsorbed hydroxyl group to produce superoxide $\left(\cdot \mathrm{O}_{2}-\right)$ and hydroxyl radicals $(\cdot \mathrm{OH})[18]$. These highly reactive oxygen species possess strong oxidation potential to decompose a variety of calcitrant organic pollutants and kill pathogenic microorganisms [24].

Self-cleaning treatment technology of fibers by incorporation of titanium dioxide nanoparticles is a new concept that has been introduced in recent years $[25,26]$. With the

fast-growing demand towards functional fibers, where fibers not only have the basic characteristics such as maintaining thermal insulation, air permeability and elasticity, but also possessing extra functionality such as selfcleaning, anti-bacterial, environmental friendly, and anti-pollution [27-40]. It is anticipated that self-cleaning fibrous materials would have significant potential in the global commercial market. Therefore, this novel concept continues to open up exciting opportunities for further research and development.

The aim of this study is to develop a simple and repeatable anchoring procedure of the $\mathrm{TiO}_{2}$ nanophase onto the polyacrylonitrile fibers. The photocatalytic self-cleaning abilities of our prepared fibers were investigated by studying the solid-phase photodegradation of the dye which is pre-adsorbed onto the $\mathrm{TiO}_{2}$-modified fibers. Also the thermal properties of pure and $\mathrm{TiO}_{2}$ coated polyacrylonitrile fibers were investigated in air and nitrogen atmosphere.

\section{EXPERIMENTAL}

\subsection{Materials}

Polyacrylonitrile fiber (PANF), is a commercial product containing polyacrylonitrile and vinyl acetate with a diameter of about $20 \mu \mathrm{m}$. The other chemicals used in the study were of reagent grade. All chemicals were from Merck Company. De-ionized water was used in all the experiments.

\subsection{Synthesis procedure}

The fiber samples were treated with acetone for $60 \mathrm{~min}$ to remove impurities and dried at room temperature for $12 \mathrm{~h}$. Titanium isopropoxide (TIP) was used as a precursor of $\mathrm{TiO}_{2}$. A solution was prepared as follows: Titanium isopropoxide $(0.01 \mathrm{~mol})$ was added to 2-isopropanol $(50 \mathrm{~mL})$ under vigorous stirring conditions and then triethylamine $(0.005 \mathrm{~mol})$ was added as a stabilizer of the solution and stirred (200 rpm) for $15 \mathrm{~min}$ under an inert environment. The required inert environment was made by argon gas flow through the system. A second solution was then prepared separately as follows: hydrochloric acid (1 $\mathrm{mL})$ and water $(0.5 \mathrm{~mL})$ were added to 2-isopropanol $(50 \mathrm{~mL})$ and mixed well by a magnetic stirrer for $10 \mathrm{~min}$. The two solutions were then mixed together and stirred vigorously for 60 min under argon gas flow. The formed $\mathrm{TiO}_{2}$ sol was transparent and quite stable

For the impregnation, the PAN fibers after being dried in a preheated oven are then immersed for $5 \mathrm{~min}$ in the $\mathrm{TiO}_{2}$ containing liquid sol. The extracted samples were then placed in $70{ }^{\circ} \mathrm{C}$ preheated oven to remove the solvent from the fiber and then heated at $200^{\circ} \mathrm{C}$ for $10 \mathrm{~min}$, to complete the formation of titanium dioxide from the precursor. Finally, the impregnated fibers were treated in de-ionized water. During this step the unattached $\mathrm{TiO}_{2}$ particles were removed from the fiber surface.

\subsection{Photocatalytic test}

The photoactivity of the titanium dioxide coated PAN fibers has been investigated by exposing the samples containing adsorbed Eosin Y (EY) to UV-Vis light. For this purpose, aqueous solution $\left(1.0 \times 10^{-5} \mathrm{M}\right)$ of Eosin yellowish (EY) was prepared. Both bare and $\mathrm{TiO}_{2}$ - covered fibers were treated in EY solution. The same amount of each sample was immersed under mild stirring in the same amount of the solution and remained overnight to complete the adsorption. The fibers were drawn out of the dyes solution and dried at room temperature. Subsequently, the so-obtained samples were exposed to UV-Vis, testing their photoactivity.

2.4 Characterization techniques 
To investigate the morphology of the pure and $\mathrm{TiO}_{2}$-modified PAN fibers, SEM (scanning electron microscopy) images were obtained on a SEM instrument (Philips, XL30) equipped with energy dispersive spectroscopic (EDS) microanalysis system to compositional analysis of the $\mathrm{TiO}_{2}$-coated polyacrylonitrile fibers. To analyze the PAN polymer chain quality before and after the treatment FTIR analysis was performed on the samples mixed with $\mathrm{KBr}$. The spectra were recorded with a Vertex70, Bruker spectrometer. X-ray diffraction measurements were performed on a Philips PW1840 diffractometer with $\mathrm{Cu}-\mathrm{K} \alpha$ radiation, scan rate $0.022 \theta / \mathrm{s}$ and within a rang of $2 \theta$ of 10 to 80 at room temperature. For photodecomposition reaction, the UV-Vis reflectance spectra were recorded at room temperature by a UV-2100 Shimadzu Spectrophotometer in the reflectance mode by investigating the evolution of the absorbance. For photocatalytic reactions, the irradiation was carried out on dry sample, by means of a high-pressure mercury lamp (HPMV 400W, Germany). The lamp yields a spectrum ranging from ultraviolet to visible radiation $(200-800 \mathrm{~nm})$. To investigate the quantity of $\mathrm{TiO}_{2}$-deposited film and thermal behavior of samples, thermogravimetric analysis was performed in air flow (ramp of $10^{\circ} \mathrm{C} / \mathrm{min}$ ) by Thermogravimetric analyzer (TGA V5.1A DuPont 2000). Differential scanning calorimetry (DSC) experiments were carried out on a Rheometric Scientific STA-625 instrument. Samples were heated up to $500{ }^{\circ} \mathrm{C}$ under nitrogen atmosphere at a heating rate of $10^{\circ} \mathrm{C} / \mathrm{min}$.

\section{Results and discussion}

\subsection{SEM and EDS analysis of $\mathrm{TiO}_{2}$ coatings}

In order to investigate the morphology of the obtained samples, comparison between the SEM images of the treated and untreated PAN fibres is illustrated in Figure 1. In the Figure 1a, on the surface of fiber, folds are evident. Figure 1b clearly shows that treated fibres are covered by a continuous and homogeneous $\mathrm{TiO}_{2}$ thin film. SEM study of $\mathrm{TiO}_{2}$ thin film deposited on polyacrylonitrile fibers, indicate that the particle size of the deposited titania on the fibres surface are less than $50 \mathrm{~nm}$ (Figure 1b). Rare and large $\mathrm{TiO}_{2}$ nanocrystals aggregates, emerging from the fiber coating, are identifiable.

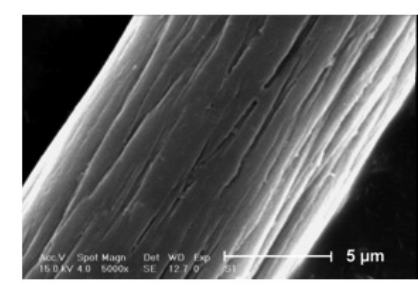

a

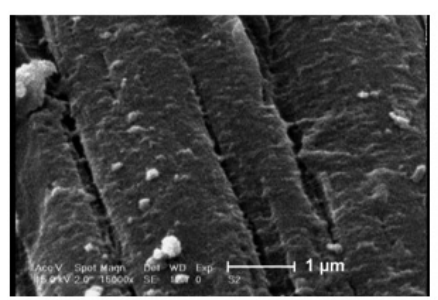

c

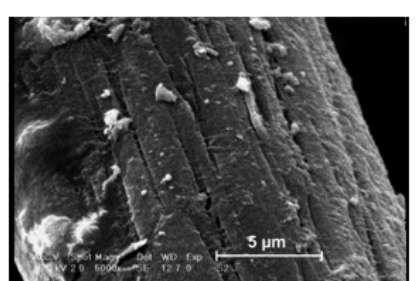

$\mathrm{b}$

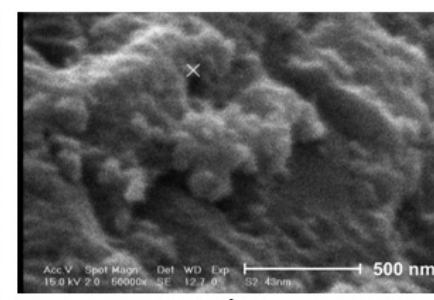

$\mathrm{d}$
Figure 1: SEM images of: (a) pure fiber, (b) $\mathrm{TiO}_{2}$-coated fiber, (c-d) enlarged $\mathrm{TiO}_{2}$-coated fibers.

In Figure 2 the EDS analysis of $\mathrm{TiO}_{2}$-covered fibres after washing are reported. On the basis of this result, it is noteworthy to observe that the deposited material consists of titanium and oxygen and after washing, remarkable amount of titania is still present on the PAN surface. This means that $\mathrm{TiO}_{2}$ particles are firmly anchored to the surface of fibres. The continuous and homogeneous nature of the $\mathrm{TiO}_{2}$ films suggests that pollutant molecules impinging the fiber- $\mathrm{TiO}_{2}$ composite will interest preferentially with the $\mathrm{TiO}_{2}$ phase covering the fibres.

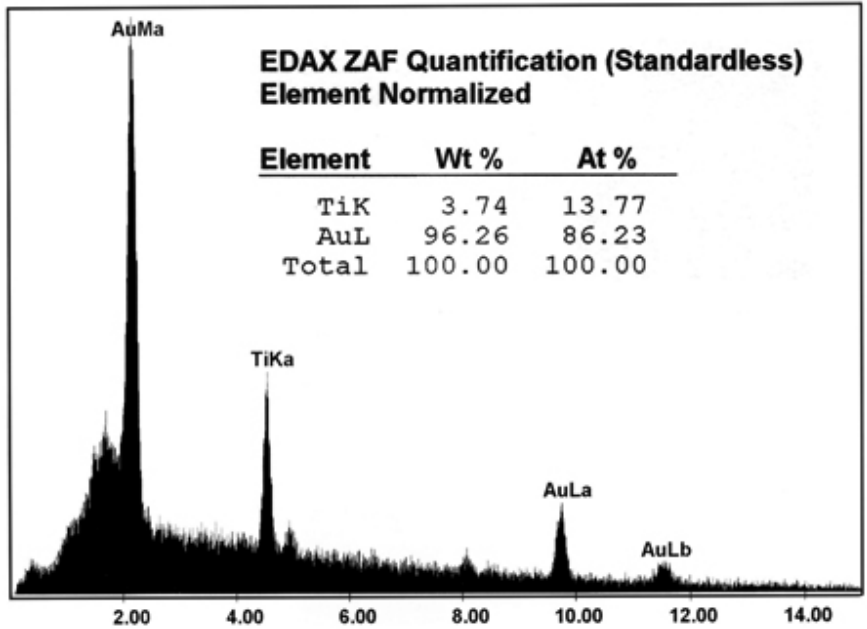

Figure 2: EDS spectra of: $\mathrm{TiO}_{2}$-coated PAN fiber after washing.

\subsection{X-ray diffraction (XRD) analysis}

The XRD patterns of pure and titania-coated PAN are reported in Figure 3. Figure 3 a reports two broad peaks and one intense peak at $17 \circ$ and $29 \circ$, respectively, which constitute the typical XRD pattern of PAN fibers [41]. Figure $3 \mathrm{~b}$ shows XRD pattern of $\mathrm{TiO}_{2}$-covered fibres. Since the amount of $\mathrm{TiO}$ was low as determined by elemental analysis $\mathrm{TiO}_{2}$ did not show a crystalline phase. This indicates that the coating of $\mathrm{TiO}_{2}$ is predominantly amorphous at low temperature, but small peaks were observed at $2 \theta=25^{\circ}, 37^{\circ}$. These are associated with diffraction peaks corresponding to anatase crystallites. Figure $3 \mathrm{c}$ and Figure 3d show XRD patterns of sol-gel derived $\mathrm{TiO}_{2}$ powders calcinated at $500{ }^{\circ} \mathrm{C}$ and $800{ }^{\circ} \mathrm{C}$, respectively. $\mathrm{TiO}_{2}$ powder calcinated at $500{ }^{\circ} \mathrm{C}$ in the spectrum of $\mathrm{TiO}_{2}$ can be easily identified as the crystal of anatase form, whereas at $800{ }^{\circ} \mathrm{C}$ can be easily taken as the crystal of rutile form.

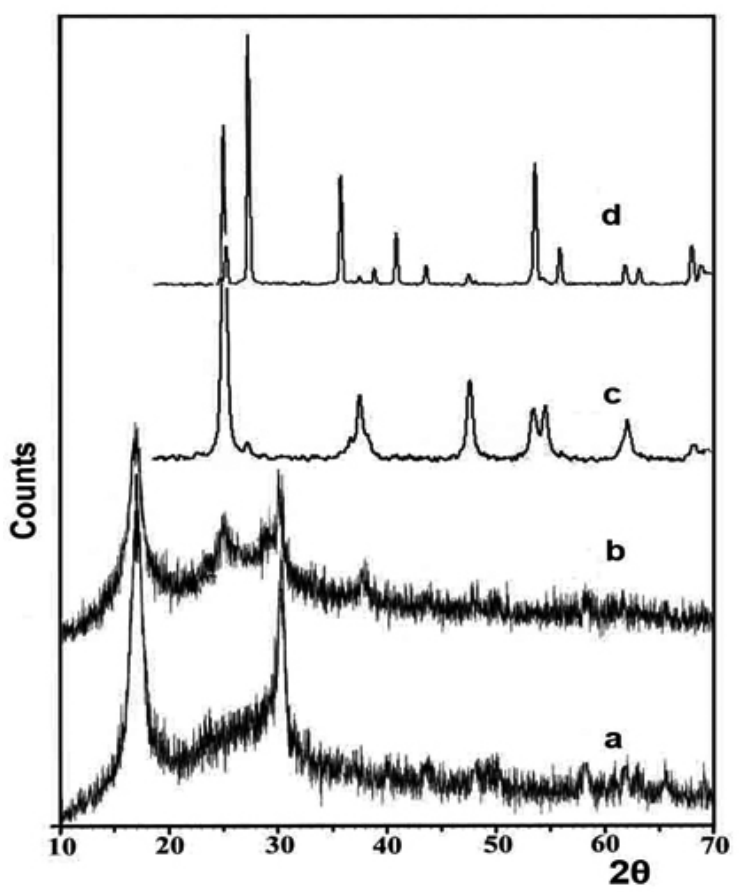

Figure 3: XRD patterns of samples: (a) pure PAN fibers, (b) $\mathrm{TiO}_{2}$-covered fibers, (c) sol -gel-derived $\mathrm{TiO}_{2}$ powder at $500^{\circ} \mathrm{C}$ (d) sol-gel - derived $\mathrm{TiO}_{2}$ powder at $700^{\circ} \mathrm{C}$. 


\subsection{FTIR spectroscope analysis}

In Figure 4, the IR spectra of the polyacrylonitrile fibers before and after $\mathrm{TiO}_{2}$ grafting are compared (curves a and b). It is apparent that peaks of the PAN fiber (Figure 4a) can be assigned as follows: $3630 \mathrm{~cm}^{-1}(\gamma \mathrm{OH}), 2941$ and $2870 \mathrm{~cm}^{-1}\left(\gamma \mathrm{C}-\mathrm{H}\right.$ asymmetric and symmetric in $\mathrm{CH}, \mathrm{CH}_{2}$, and $\mathrm{CH}_{3}$ groups), $2244 \mathrm{~cm}^{-1}(\gamma \mathrm{C} \equiv \mathrm{N}), 1741 \mathrm{~cm}^{-1}(\gamma \mathrm{C}=\mathrm{O}), 1455 \mathrm{~cm}^{-1}\left(\delta \mathrm{CH}_{3}\right.$ and $\left.\delta_{\mathrm{S}} \mathrm{CH}_{2}\right), 1374$ $\mathrm{cm}^{-1}\left(\delta \mathrm{CH}_{3}\right.$ symmetric in $\left.\mathrm{CCH}_{3}\right), 1240 \mathrm{~cm}^{-1}(\gamma \mathrm{C}-\mathrm{N}), 1070 \mathrm{~cm}^{-1}(\delta \mathrm{C}-\mathrm{N})$, and $535 \mathrm{~cm}^{-1}(\delta \tau \mathrm{C}=\mathrm{O})$, where $\gamma$ represents a stretching vibration, $\delta$ a bending vibration, $\delta_{\mathrm{S}}$ a scissor vibration, and $\delta_{\tau}$ a twisting vibration [42].

The spectrum of the fibers after grafting (Figure $4 \mathrm{~b}$ ), is substantially unaltered. This means that due to the low external surface area of the supporting fibers, the IR spectroscopy is not informative on the grafting mechanism at all. It is quite remarkable that IR spectrum of the treated sample is totally dominated by the spectrum of the fiber, the contribution of the $\mathrm{TiO}_{2}$ phase (which should appear at $\gamma<700 \mathrm{~cm}^{-1}$ ) is also negligible.

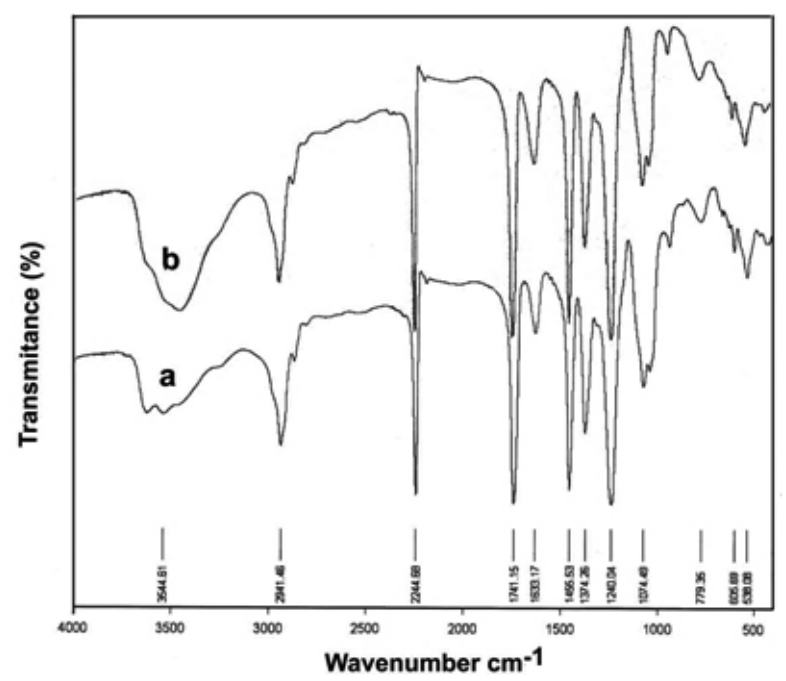

Figure 4: FTIR spectra of: (a) pure PAN fibers, (b) $\mathrm{TiO}_{2}$-covered fibres

\subsection{Thermal analysis}

Stabilization of PAN is commonly performed in air between 200 and 300 ${ }^{\circ} \mathrm{C}$. During this process, PAN undergoes a number of physical and chemical changes due to a variety of exothermic chemical reactions, including cyclization, dehydrogenation, oxidation, cross linking and fragmentation. Among them, the cyclization reactions which convert PAN into an infusible stable ladder polymer are of most importance. The cyclization reactions seem not to depend on atmosphere, because they can proceed in either an oxidizing atmosphere or an inert atmosphere. However, as is known that oxygen is necessary for the stabilization of PAN precursor, in order to get high performance carbon fibers, the PAN precursor fibers must be stabilized in an oxidizing atmosphere which is typically air [4]. A greater stability will be obtained when PAN is stabilized in air. This is mainly contributed to the reactions with oxygen. These reactions, mainly including dehydrogenation and oxygen uptake reactions are seriously influenced by the diffusion of oxygen.

\subsubsection{Differential scanning calorimetry (DSC) analyses}

Figure 5 shows the DSC curves of PAN and $\mathrm{PAN} / \mathrm{TiO}_{2}$ heated at $10^{\circ} \mathrm{C} /$ min in nitrogen atmosphere. PAN exhibits a sharp single exothermic peak initiated at about $235^{\circ} \mathrm{C}$ and centered at $335^{\circ} \mathrm{C}$, as well as $\mathrm{PAN} / \mathrm{TiO}$, shows a exothermic peak initiated at about $235^{\circ} \mathrm{C}$, and centered at $341^{\circ} \mathrm{C}$. The initiation temperature $(\mathrm{Ti})$, finish temperature $\left(\mathrm{T}_{\mathrm{f}}\right)$, maximum exothermic temperature $(\mathrm{Tm})$, and evolved heat $(\Delta \mathrm{H})$ are shown in Table 1. It is known that the cyclization reactions in the PAN follow a free radical mechanism and only can be initiated at a higher temperature. Thus, the single exothermic peak found would be attributed to the overlapping of the free radical cyclization reactions and other exothermic reactions at the higher temperature [43].
Table 1: DSC data for PAN and PAN-TiO

\begin{tabular}{|l|c|c|c|c|}
\hline Sample & $\mathrm{Ti}\left({ }^{\circ} \mathrm{C}\right)$ & $\mathrm{T}_{\mathrm{f}}\left({ }^{\circ} \mathrm{C}\right)$ & $\mathrm{T}_{\mathrm{m}}\left({ }^{\circ} \mathrm{C}\right)$ & $\Delta \mathrm{H}\left(\mathrm{j} \cdot \mathrm{g}^{-1}\right)$ \\
\hline PAN & 235 & 360 & 335 & 391.33 \\
\hline $\mathrm{PAN} / \mathrm{TiO}_{2}$ & 235 & 365 & 341 & 366.65 \\
\hline
\end{tabular}

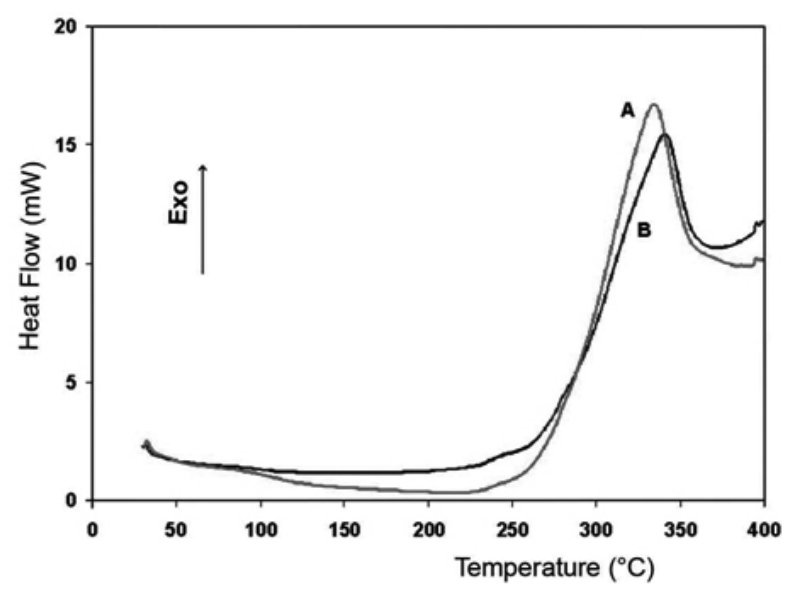

Figure 5: DSC curve of : (A) PAN and (B) $\mathrm{PAN}^{-\mathrm{TiO}_{2}}$

The evolution of a large amount of heat in this case has been attributed to the cyclization of nitrile groups and depends upon nature of the polymer as well as the experimental conditions. Cyclization is highly exothermic process and for pure PAN fibers, is occurred at high temperatures in a narrow range. It has a very high energy release rate, but it is reduced slightly when $\mathrm{PAN} / \mathrm{TiO}_{2}$ composite are employed. The process of stabilization is achieved by formation of a ladder polymer through nitrile polymerization $[1,43]$.

\subsubsection{Thermogravimetric analysis (TGA)}

The TGA analysis of the polyacrylonitrile fibre carried out under an air atmosphere and $\mathrm{N}_{2}$ at a heating rate of $10{ }^{\circ} \mathrm{C} / \mathrm{min}$. The TGA analysis of the polyacrylonitrile fiber in air atmosphere (Figure 6 and Figure 7) can be roughly divided into three steps according to the extent of weight loss [43-45]. The first step is up to about $250{ }^{\circ} \mathrm{C}$, where weight loss is very small. In combination with the DSC results, it is inferred that there is only cyclization occurring in this step, since this reaction theoretically does not cause any weight loss [46]. The second step is up to about $300{ }^{\circ} \mathrm{C}$. During this step, the rate of weight loss becomes quite rapid, which is mainly due to the dehydrogenation. It is apparent that the weight loss of PAN/TiO is larger than that of PAN. It implies that $\mathrm{TiO}_{2}$ has promoted the dehydrogenation to some extent. In the last step, the rate of weight loss is quite steady; but contrarily the weight loss of PAN becomes larger than that of $\mathrm{PAN} / \mathrm{TiO}_{2}$. In this step, on the one hand fragmentation of polymer chains occurs producing volatile particles leading to weight loss.

After combustion of all organic part, the residual amount ( $27 \%$ by weight $)$ corresponds to $\mathrm{TiO}_{2}$. From this result, it is evident that the TGA technique in air allows to directly evaluating the amount of $\mathrm{TiO}_{2}$ covering the PAN fibers, as obtained by the synthesis procedure described before. 


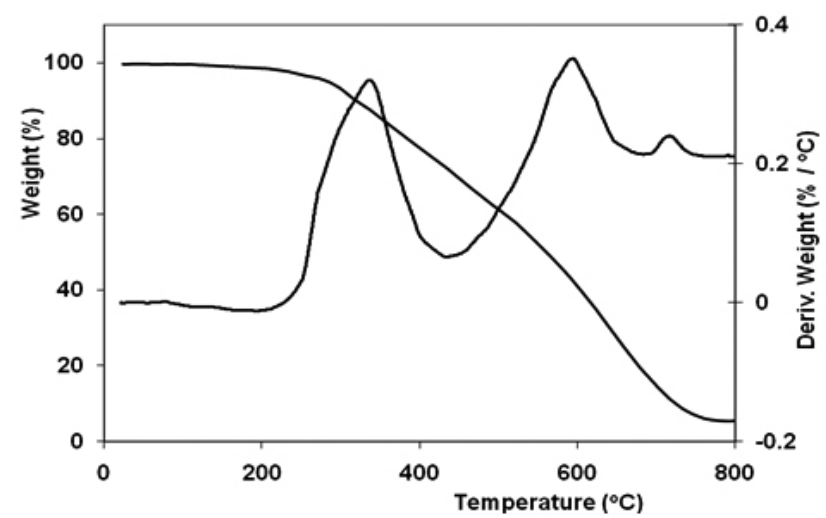

Figure 6: TGA and DTGA curves of the pure PAN fiber.

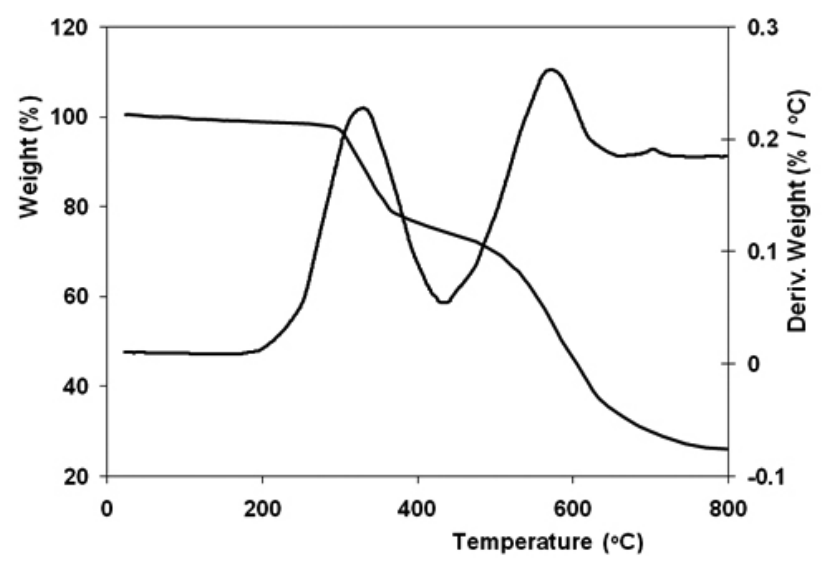

Figure 7: TGA and DTGA curves of the $\mathrm{TiO}_{2}$-coated fibres in air. The residual weight of the sample, recorded at $800{ }^{\circ} \mathrm{C}$, is related to the $\mathrm{TiO}_{2}$ content, after that the PAN fiber burning has taken place.

The TGA analysis of the PAN fiber and $\mathrm{TiO}_{2}$-coated fiber in $\mathrm{N}_{2}$ atmosphere is shown in Figure 8 and Figure 9. The TGA analysis of the $\mathrm{TiO}_{2}-$ coated fiber shows four decomposition steps [47]. The first appears clearly from TG analysis, and is located between $60-250{ }^{\circ} \mathrm{C}$ with mass change of $15 \%$ that nearly correspond to the water of hydrous $\mathrm{TiO}_{2}$. The second step appears between $250-290{ }^{\circ} \mathrm{C}$ with a sudden and intense liberation of heat, corresponding to a mass change of $40 \%$. This exothermic peak is characteristic to the olygomerization of nitrile groups of PAN. The third exothermic peak is located between 290 and $450{ }^{\circ} \mathrm{C}$ with mass change of $68 \%$, it may be due to the partial evaporation of $\mathrm{NH}_{3}$ and $\mathrm{HCN}$. Finally, the fourth exothermic peak located between 450 and $750{ }^{\circ} \mathrm{C}$, corresponding to mass change of $78 \%$ may be due to complete evaporation of polymer chain fragments.

The total weight loss for PAN in air up to $800^{\circ} \mathrm{C}$ was $95 \%$, in nitrogen only $56 \%$. This big difference is explained by cyclization and carbonization processes which lead to the formation of carbon fibers [44].

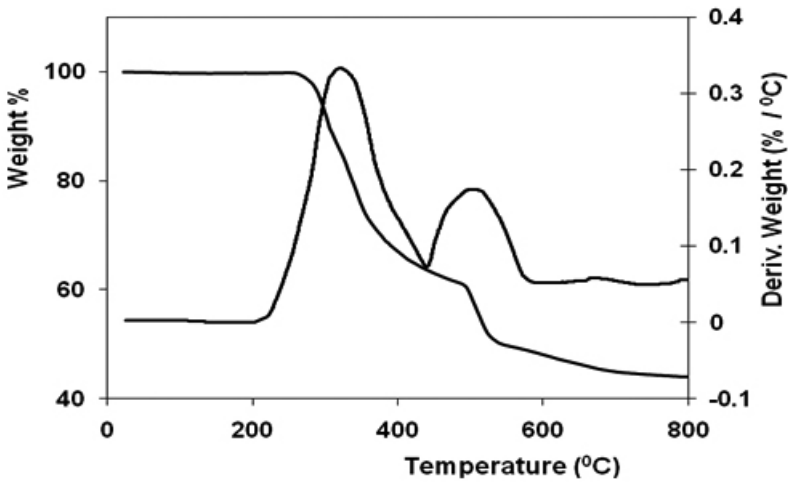

Figure 8: TGA and DTGA curves of the pure PAN fiber in $\mathrm{N}_{2}$.

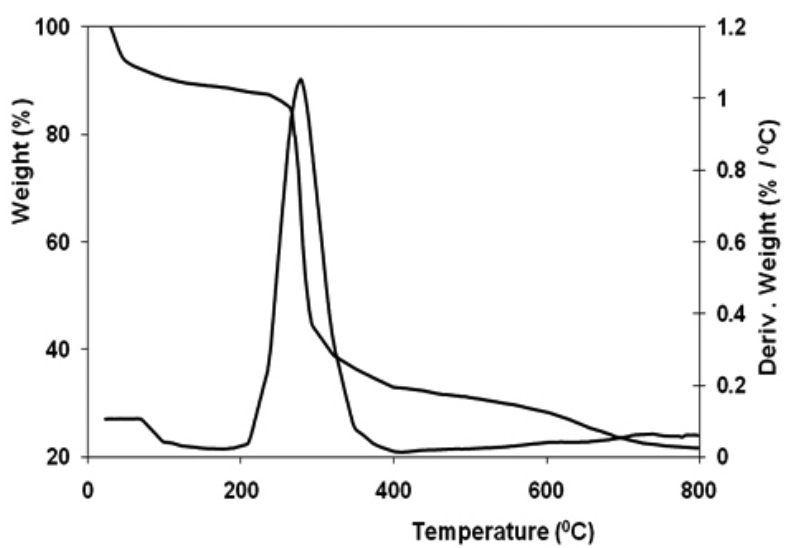

Figure 9: TGA and DTGA curves of the $\mathrm{TiO}_{2}$-coated fibres in $\mathrm{N}_{2}$.

\subsection{Photocatalytic self-cleaning study}

The photoactivity of the titanium dioxide coated PAN fibers has been investigated by exposing the samples containing adsorbed Eosin Y to UV-Vis light. The UV-Vis reflectance spectra obtained on the dried samples before (spectrum a) and after illumination (spectrum b-f) are reported in Figure 10. From Figure10a, it can be observed that the absorption bands in the 400$600 \mathrm{~nm}$ intervals due to adsorption of Eosin Y, change rapidly, because supported $\mathrm{TiO}_{2}$ promotes the catalytic photodegradation (spectrum b-f). This is not unexpected since the photocatalytic activity of $\mathrm{TiO}_{2}$ is well known $[48,49]$. The disappearance rate of the band due to Eosin $\mathrm{Y}$ adsorbed on the $\mathrm{TiO}_{2}$-covered fibers is much higher than that observed in case of untreated fibers (Figure 11). Of course the photodegradation effect is lower than that observed on P25 (Figure 12), which is the best $\mathrm{TiO}_{2}$ catalyst. However, the photocatalytic activity of titania is dependent on both particle size and degree of crystallization [50]. 


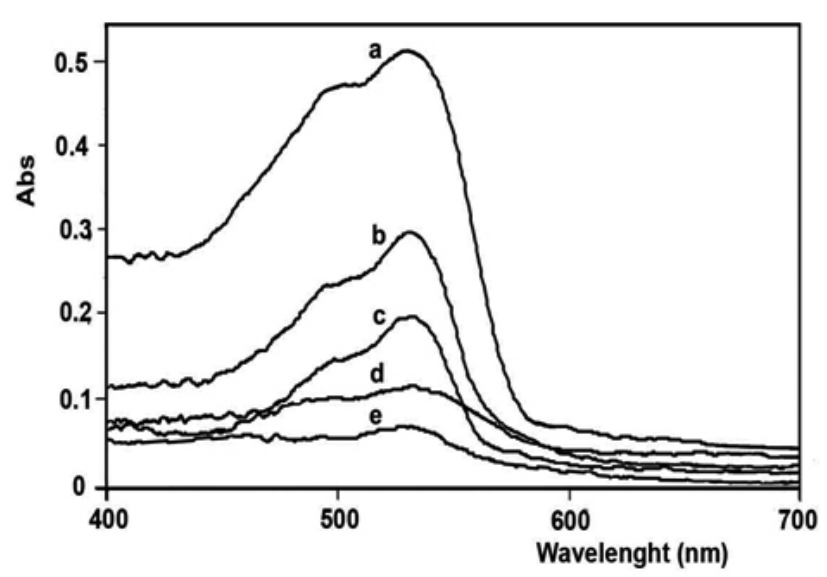

Figure 10: UV-vis reflectance spectra changes of Eosin $\mathrm{Y}_{\text {on }} \mathrm{TiO}_{2}$-coated fibres at room temperature, under UV-Vis light irradiation: no exposure (curve a), irradiation for $2 \mathrm{~h}$ (curve b), $4 \mathrm{~h}$ (curve c), $6 \mathrm{~h}$ (curve d), and $8 \mathrm{~h}$ (curve e).

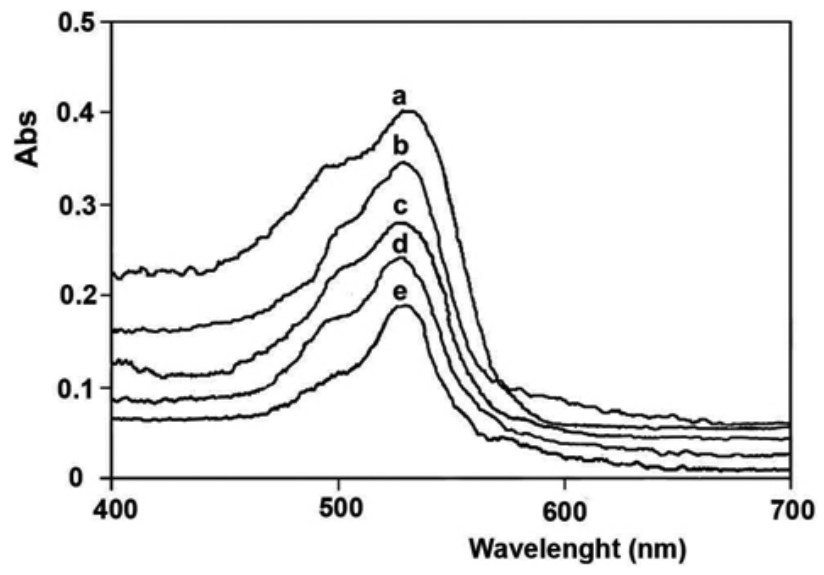

Figure 11: UV-Vis reflectance spectra changes of Eosin $\mathrm{Y}$ on pure polyacrylonitrile fibres at room temperature, under UV-Vis light irradiation: no exposure (curve a), irradiation for $2 \mathrm{~h}$ (curve b), $4 \mathrm{~h}$ (curve c), $6 \mathrm{~h}$ (curve d), and $8 \mathrm{~h}$ (curve e).

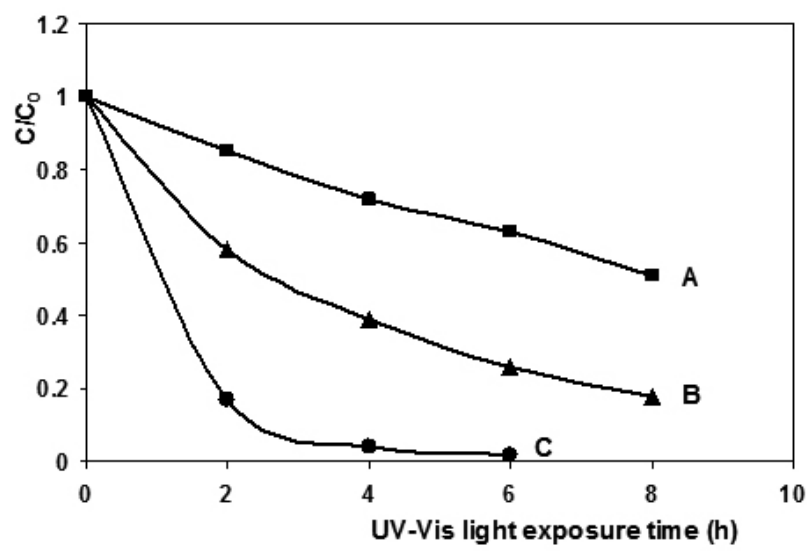

Figure 12: Time dependence of the surface concentration of adsorbed Eosin Y upon light exposure. (A) untreated fibres, (B) Photocatalytic activity of $\mathrm{TiO}_{2}$-coated fibres, and (C) $\mathrm{P} 25$.

To test the durability of photocatalytic activity of the $\mathrm{TiO}_{2}$-coated fibers, the photodegradation process was repeated for three more cycles on the same sample. Figure 13 shows the photocatalytic efficiency of the $\mathrm{TiO}_{2}$-modified fiber for the photodegradation of EY, which is unchanged relatively upon repeating cycles. These results suggest that $\mathrm{TiO}_{2}$ losses from the fibers surface for each impregnation of stain (EY) is ignorable and $\mathrm{TiO}_{2}$ particles were adhered compactly to the fibers.

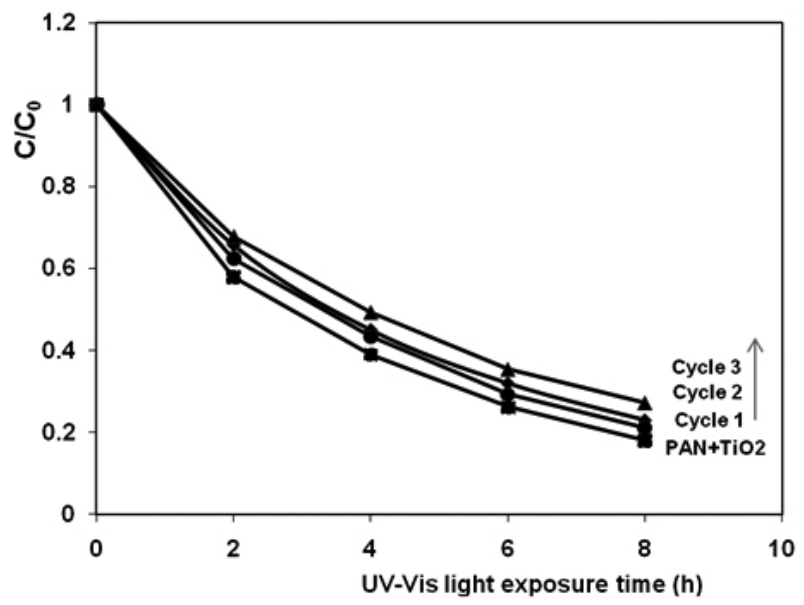

Figure 13: Photocatalytic efficiency of $\mathrm{TiO}_{2}$-modified PAN fibers upon repeated EY adsorption-illumination cycles.

From all these data, it is evident that supported $\mathrm{TiO}_{2}$ particles promote the photodegradation process and the high surface area associated with the small particle size ensures a favorable condition for a relatively fast degradation and performance of self cleaning.

\section{CONCLUSION}

Anatase nanocrystals were successfully synthesized and deposited on polyacrylonitrile fibers with significant photocatalytic self-cleaning activity using the sol-gel process. The $\mathrm{TiO}_{2}$ nanoparticles, have been found to form a homogeneous thin film on the fiber surface, which shows efficient photocatalytic properties when exposed to UV-Vis light. Self-cleaning properties were monitored by diffuse reflectance spectroscopy. The $\mathrm{TiO}_{2}$-covered polyacrylonitrile fibres show high photocatalytic efficiency in decomposing the pre-adsorbed Eosin $\mathrm{Y}$ under UV-Vis light. $\mathrm{TiO}_{2}$-covered fibers promote the photodegradation process and the high surface area associated with the small particle size ensures a favorable condition for a relatively fast degradation. The TGA curve of $\mathrm{PAN} / \mathrm{TiO}_{2}$ showed a slight increase of weight loss in the second step and a significant decrease of weight loss in the third step. It implied that the dehydrogenation and oxygen uptake reactions would be promoted by the $\mathrm{TiO}_{2}$ to some extent. Cyclization is highly exothermic process and for pure PAN fibers, is occurred at high temperatures in a narrow range. It has a very high energy release rate, but it is reduced slightly when $\mathrm{PAN} / \mathrm{TiO}_{2}$ composite are employed.

\section{ACKNOWLEDGEMENTS}

The authors are grateful to University of Guilan for financial assistance of this research project. 


\section{REFERENCES}

1. A. Sedghi, R. E. Farsani,, A. Shokuhfar, J. Mater. Process. Tech. 198, 60, (2008).

2. A. K. Gupta, D. K. Paliwal, P. Bajaj, Polym. Rev. 31, 1, (1991).

3. P. Morgan, Carbon fibers and their composites. New York: Taylor \& Francis; 2005

4. M. S. A. Rahaman, A. F. Ismail, A. Mustafa , Polym. Degrad. Stab. 92, 1421, (2007)

5. J. C. Masson, Acrylic Fiber Technology and Applications. Marcel Dekker Inc., New York, 1995.

6. L. Ji, Y. Yao, O. Toprakci, Z. Lin, Y. Liang, Q. Shi, A. J. Medford, C. R. Millns, X. Zhang, J. Power. Sources. 195, 2050,(2010).

7. P. Miao, D. Wu , K. Zeng, G. Xu , C. Zhao, G. Yang, Polym. Degrad. Stab. 95, 1665, (2010).

8. A. Sedghi, R. E. Farsani, , A. Shokuhfar, j. Mater. Proce. technol. 198, 60, (2008).

9. Z. Zhou, K. Liu , C. Lai, L. Zhang, J. Li, H. Hou, D. H. Renekerc, H. Fong, Polymer. 51, 2360, (2010).

10. Y. H. Choi, C. M. Choi, D. H. Choi, Y. Paik, B. J. Park, Y. K. Joo, N. J. Kim, J. Memb. Scie. 371, 84, (2011).

11. D. Xie, Z. Shi, Z. Su, and R. Wang, , Polym. Mater. Sci. Eng. 11, 5, (1995).

12. T. Takahakgi, I. Shimada, M. Fukuhara. K.Morita, and A.Ishitani, , J. Polym. Sci.: Part A: Polym. Chem. Edn, 24, 3101, (1986).

13. L. H. J .Peebles, A. W. Snow, W. C. Peters, J. Polym. Sci.: Part A: Polym. Chem. Edn, 33, 2069, (1995).

14. J. Xue Thomas, A. Michael, A. Wilkie McKinney \& Charles, polym. Degrade. stab, 58, 193, (1997).

15. M. Gratzel, Nature. 414, 338, (2001).

16. E. Allain, S. Besson, C. Durand, M. Moreau, T. Gacoin, J. P. Boilot, Adv. Funct. Mater.17, 549, (2007).

17. M. C. Long, W. M. Cai, J. Cai, B. X. Zhou, X. Y. Chai, Y. H. Wu, J. Phys. Chem., B 110, 20211, (2006).

18. M. R. Hoffmann, S. T. Martin, W. Choi, D. W. Bahnemannt, Chem. Rev. 95, 69, (1995).

19. M. C. Long, W. M. Cai, Z. P. Wang, G. Z. Liu, Chem. Phys. Lett. 420, 71, (2006).

20. S. Yin, B. Liu, P. L. Zhang, T. Morikawa, K. Yamanaka, T. Sato, J. Phys. Chem. C 112, 12425, (2008).

21. H. Taoda, Res. Chem. Intermed. 34, 417, (2008).

22. S. Yuan, Q. R. Sheng, J. L. Zhang, H. Yamashita, D. N. He, Microporous. Mesoporous. Mater. 110, 501, (2008).

23. A. Fujishima, T. N. Rao, D. A. Tryk, J. Photochem. Photobiol. C: Photochem. Rev. 1, 1, (2000).
24. W. Choi, Catal. Surv. Asia 10, 16, (2006).

25. M. Anpo, T. Shima, S. Kodma, Y. Kubokawa, J. Phys. Chem. 91, 4305, (1987).

26. C. R. Bickmore, K. F. Waldner, R. Baranwal, T. Hinklin, D. R. Treadwell, R.M. Laine, J. Eur. Ceram. Soc. 18, 287, (1998).

27. K. Hashimoto, H. Irie, A. Fujishima, Jpn. J. Appl. Phys. 44, 8269, (2005).

28. A. Fujishima, X. Zhang, C. R. Chem. 9, 750, (2006).

29. I. P. Parkin, R. G. Palgrave, J. Mater. Chem. 15, 1689, (2005).

30. Y. Kikuchi, K. Sunada, T. Iyoda, K. Hashimoto, A. Fujishima, J. Photochem. Photobiol. A: Chem. 106, 51, (1997).

31. I. Sopyan, M. Watanabe, S. Murasawa, K. Hashimoto, A. Fujishima, J. Electroanal. Chem. 415, 183, (1996).

32. Y. Dong, Z. Bai, L. Zhang, R. Liu, T. Zhu, J. Appl. Polym. Sci. 99, 286 (2006).

33. H. Yu, S. C. Lee, J. Yu, C. H. Ao, J. Mol. Catal. A: Chem. 246, 206 (2006).

34. B.Y. Jia, L.Y. Duan, C.L. Ma, C.M. Wang, Chin. J. Chem. 25,553, (2007).

35. S. Wang, W. Hou , L. Wei, H. Jia, X. Liu , B. Xu, Surf. Coat. Technol 202, 460, (2007).

36. W.A. Daoud, J.H. Xin, J. Am. Ceram. Soc. 87,953, (2004).

37. M. Peplow, Nature. 429, 620, (2004).

38. W.A. Daoud, J.H. Xin, Y.H. Zhang, K.H. Qi, J. Non-Cryst. Solids. $351,1486,(2005)$

39. K.H. Qi, W.A. Daoud, J.H. Xin, C.L. Mak, W.S. Tang, W.P. Cheung, J. Mater. Chem. 16,4567, (2006).

40. W.A. Daoud, J.H. Xin, Y.H. Zhang, Surf. Scie. 599, 69, (2005).

41. P. J. Sanchez-Soto, M. A. Aviles, J. C. del Rio, J. M. Gines, J. Pascual, J. L. Perez-Rodriguez, J. Anal. Appl. Pyrolysis. 58, 155, (2001).

42. S. Deng, R. Bai, J.P. Chen, J. Colloid. Interf. Sci., 260, 265, (2003).

43. Q. Ouyang, L.Cheng, H. Wang, L. Kaixi, Polym Degrad Stab, 93, 1415, (2008).

44. M. Herrera, M. Wilhelm, G. Matuschek, A. Kettrup, J. Anal. Appl. Pyrol. 58, 173, (2001).

45. B. Grzyb, J. Machnikowski, J. V. Weber, A. Koch, O. Heintz, J. Anal. Appl. Pyrol. 67, 77, (2003).

46. P. Bajaj, T. V. Screekumar, K. Sen, , Polymer. 42, 1707, (2001).

47. I. M. Ali, A. A. El-Zahhar, E. S. Zakaria, J. Radio. Anal. Nucl. Chem, 264, 637, (2005).

48. F. Sandola, V. Balzani, in: N. Serpone, E. Pelizzetti (Eds.), Photocatalysis_-Fundamentals and Applications, John Wiley \& Sons, New York. 1989.

49. S. Kutsuna, M. Toma, K. Takeuchi, T. Ibusuki, Environ. Sci. Technol. 33, 1071, (1999).

50. Z. Zhang, C. C. Wang, R. Zakaria, J. Y. Ying, J. Phys. Chem. B 102 , 10871, (1998). 